\title{
ASPECTS OF MELT COMPOSITION, CRYSTALLIZATION, METASOMATISM AND DISTRIBUTION, SHOWN BY MANTLE XENOLITHS FROM THE MATSOKU KIMBERLITE PIPE.
}

\author{
Harte, ${ }^{(1)}$ B.; Matthews, ${ }^{(1)}$ M.B.; Winterburn, ${ }^{(2)}$ P.A.; and Gurney, ${ }^{(3)}{ }_{J J}$.
}

(1) Dept. Geology and Gieophysics, University of Edinburgh, Edinburgh EH9 3JW, Scotland, U.K.; (2) Anglo-American Research Laboratories, Johannesburg, South Africa; (3) Dept. of Geochemistry, University of Cape

Town, Rondebosch 7700, South Africa.

\section{Introduction}

The nature and mobility of mantle melts and their relationships to mantle metasomatism are important topics of extensive recent debate. The garnetiferous peridotite-pyroxenite xenoliths from Matsoku have been of particular interest in this context (e.g.Harte et al.,1975, 1987), and although somewhat unusual for xenoliths from kimberlite, it is evident that they record similar processes of formation to those associated with 'dike' intrusion and metasomatism in many mantle xenoliths from basalts. This paper summarises the most recent work on the Matsoku xenoliths, which has led to clarification of: the chemical character and origin of the melt involved in injection and metasomatism, textural aspects of melt distribution and crystallisation, the production of 'cumulate' chemical compositions, and the relative roles of diffusion and infiltration in metasomatism.

\section{Trace element evidence of melt compositions}

Ion microprobe studies of trace element compositions in the garnets and clinopyroxenes in the pyroxenite sheets ('dikes') and metasomatised rocks have been carried out on a Cameca IMS4f ion microprobe (Edinburgh University/NERC facility). An $O^{-}$primary ion beam was used, and positive secondary ions were measured at high energy (to reduce molecular overlaps) and standardised against NBS glass and natural garnet and clinopyroxene standards.

Measurements were made principally for $Y, Z r$ and REE and show considerable similarity between the compositions of Matsoku garnet

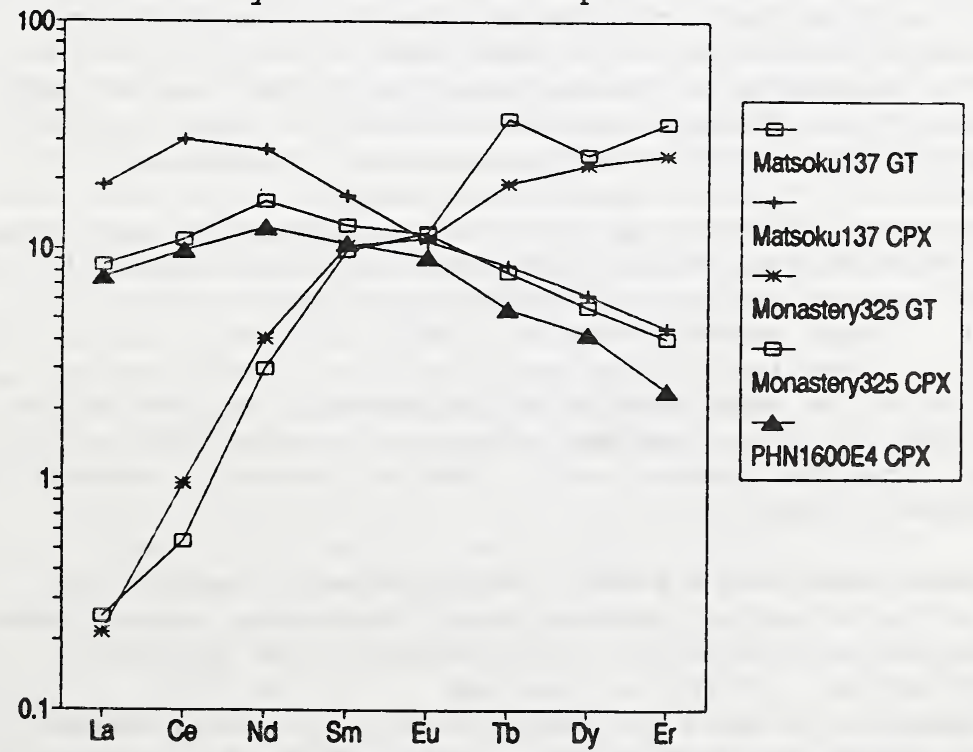

Fig. 1 Chondrite normalised REE abundances 
and clinopyroxene formed in equilibrium with intruding and infiltrating melt, and those of Cr-poor megacrysts from kimberlites. REE data for a garnetiferous pyroxene-rich 'dike' (specimen LBM 137 documented by Harte et al., 1987) are shown in Fig. 1, where they are compared with Edinburgh ion microprobe

data for coexisting garnet and clinopyroxene in a megacryst from the Monastery mine (provided by R. O. Moore), and with cpx megacryst PHN1600E4 (data from Kramers et al., 1981).

Fig. 1 demonstrates the considerable similarity between the trace element contents of the Matsoku 'dike' phases and those of the megacrysts, and thereby suggests that the melt intruding and metasomatising the Matsoku peridotites was of very similar composition to that from which the Cr-poor megacrysts crystallised. Estimation of the Matsoku melt composition using crystal-liquid partition coefficients (Hanson, 1980) yields a melt of OIB-like (primitive basanite) characteristics, as similarly determined for Cr-poor megacrysts (Harte, 1983; Jones 1987). Thus despite the lithospheric P-T estimates (ca. $35 \mathrm{kbs}$ and $1000^{\circ} \mathrm{C}$ ) of the Matsoku xenoliths, there is evidence of intrusion and metasomatism by a melt of asthenospheric origin, similar to that suggested to metasomatise high-temperature deformed peridotites (Harte, 1983).

Melt textures in pyroxenite 'dikes' and modally metasomatised rocks. Partially preserved igneous textures involving both euhedralsubhedral and interstitial-xenomorphic pyroxene crystals are found in some of the intrusive pyroxene-rich 'dikes'. 'These suggest pseudomorphing of the shape of interstitial melt patches by the interstitial-xenomorphic crystals.

Particularly good evidence of melt distribution and melt geometry has been found in the textures of ilmenite concentrations in some modally metasomatised rocks. Irregular and sometimes elongate patches of ilmenite (up to $1.5 \mathrm{cms}$ long) were seen with curious cuspate and spiky margins, with suggestions that they might represent melt pseudomorphs.. A study of dihedral angles for ilmenite grains between two olivines and between two orthopyroxenes was undertaken, and yielded a very wide spread of values with evidence of bimodal distribution in each case. For olivine the ilmenite dihedral angles were concentrated at 50-60 and $90-100^{\circ}$, while the bimodes for orthopyroxene were at $60-70^{\circ}$ and $110-120^{\circ}$. The dihedral angles close $60^{\circ}$ were interpreted, following experimental work, as those originally belonging to the melt now pseudomorphed by the ilmenite; whilst the concentration of values around $90-120^{\circ}$ were tentatively interpreted as those reflecting the texturally equilibrated value of ilmenite itself (Harte and Matthews, 1989). Experimental work at $1200^{\circ} \mathrm{C}$ and $5 \mathrm{kbs}$ has recently been completed on ilmenite-olivine and ilmenite-orthopyroxene aggregates to check the equilibrium solid dihedral angles of the ilmenite, and this has given values of approximately $100^{\circ}$ and $120^{\circ}$ for olivine and ilmenite respectively, thereby strongly supporting the above interpretations..

The above features indicate a number of important conclusions:

1) The rate of solid-solid textural equilibration, even at the ambient temperatures of $\mathrm{ca} .1000{ }^{\circ} \mathrm{C}$ indicated by the Matsoku xenoliths (Harte et al. 1987), is limited.

2) The distribution of melt porosity is clearly non-uniform on the $1-10 \mathrm{cms}$ scale at higher melt fractions, and involves ' patches' as well as channels.

3) The low dihedral angles for melt-olivine-olivine show that extremely small amounts of melt should adopt a connected geometry through a olivine-rich matrix (see also Beere, 1975). 
4) During crystallisation original melt volumes may be replaced by single minerals, demonstrating mobility of melt components during crystallisation, which would be facilitated by the melt connectivity noted under (3).

5) The migration of melt components during melt crystallisation means that even late stage interstitial melt pools do not preserve their bulk melt composition during crystallisation. These features are similar to those seen in layered cumulate bodies, and partly account for the cumulate chemical composition characteristics of 'dikes' in mantle xenoliths.

6) Features (4) and (5) above provide an explanation of the similarity of textures between some mantle rocks showing modal metasomatism and those of cumulates.

\section{Garnet cracking and metasomatism in petrographically unmodified wallrocks.}

The wallrocks to some pyroxenite 'dikes' show no evidence of modal metasomatism or other change in routine petrographic examination, but are clearly metasomatised to mineral compositions similar to those in the 'dikes'. In view of the apparently unmodified textures, it was originally thought that the metasomatism was largely diffusion controlled. However, the low dihedral angles of the melt noted above, clearly make it possible for melt in low volumes to infiltrate and be drawn into the wallrocks along mineral grain edges, without obvious textural change.

Minerals in these wallrocks have been chemically changed to largely homogeneous compositions, except for garnets, which may show core compositions typical of unmetasomatised peridotite (Harte et al., 1987). Recent extremely detailed electron microprobe analysis and back scattered electron imaging has shown the detailed pattern of the change (principally Fe-Ti enrichment) in garnet composition. Narrow, quite sharply defined zones of chemically modified (Fe-Ti rich) garnet transect regions of little modified garnet. These features imply that during melt infiltration the garnets cracked, and that melt penetrated along the fractures; then, following cracking, garnet growth occurred with Fe-Ti rich compositions controlled by the infiltrated melt, and the fractures were filled with new garnet. These 'healed cracks' are not visible in normal optical examination and are distinct from the visible fractures formed during entrainment and eruption of the xenoliths. The larger healed cracks may show fringes of smaller healed cracks, and it is evident that the cracking and regrowth of the garnet extensively controlled the change in garnet chemistry. The influence of volume diffusion is therefore far less than it originally appeared to be, though probable diffusion-controlled halos of lesser chemical change do occur around the healed cracks and the margins of the garnets.

\section{References}

Beere, W. (1975) Acta Metallurgica 23, 131-138.

Hanson, G.N. (1980) Ann Rev of Earth and Planetary Science 8, 371406 .

Harte, B. (1983) In Hawkesworth, C.J. and Norry,M.J., (eds), Contintental basalts and mantle xenoliths, Shiva, 46-99.

Harte, B., and Matthews, M.B. (1989) $28^{\text {th }}$ International Geological Congress Abstracts, volume 2, 32-33.

Harte, B., Cox, K.G., and Gurney, J.J. (1975) Physics and Chemistry of the Earth 9, 477-508.

Harte, B., Winterburn, P.A., and Gurney, J.J. (1987) In Menzies, M.A., and Hawkesworth, C.J., (eds), Mantle Metasomatism, 54-220. Jones, R.A. (1987) In Nixon, P.H., (ed), Mantle Xenoliths, 711-724. Kramers, J.D., Smith, C.B., Harmon, R.S., and Boyd, F.R. (1981) Nature 291, 53-56. 